\title{
Sensitive elements based on bacteriorhodopsin for fiber-optics sensors of chemical components
}

\author{
Yosyp P. Sharkany ${ }^{\mathrm{a}, \mathrm{b}}$, Ivan I. Trikur ${ }^{\mathrm{a}}$, Serhiy A. Korposh ${ }^{\mathrm{a}, \mathrm{b}}$, Jeremy J. Ramsden ${ }^{\mathrm{b}}$ \\ ${ }^{a}$ Institute of Solid-State Physics \& Chemistry, Uzhgorod National University, \\ Voloshina St., 54, Uzhgorod, 88000, Ukraine; \\ ${ }^{\mathrm{b}}$ Cranfield University at Kitakyushu, KSRP, 2-5-4F Hibikino, Wakamatsu-ku, \\ Kitakyushu 808-0135, Japan
}

\begin{abstract}
The sensitive thin film elements based on bacteriorhodopsin in polymeric matrixes for the multichannel fiber-optical sensor system of measurement of chemical composition of gas mixtures are offered. It is shown, that modification of films compositions by the photosensitizing chemical additives changes the photocycle parameters and exhibits selectivity to the effect of various gases.
\end{abstract}

Keywords: Optical fiber sensor, bacteriorhodopsin, photosensitizing additives.

\section{INTRODUCTION}

The simultaneous determination of several chemical components of low concentrations in gas mixtures or in the liquid solutions, is the actual task for today and covers the very wide applications area of an ecological monitoring, biomedical researches, and is also useful for determination of parameters of the environments in various technological processes. The most important stages for the development of measuring systems are the choice of elements_sensitive to the influence of chemical components, the principles and scheme of measurement.

From the point of view of practical application of separate chemical sensors the most convenient are the fiber-optical sensors ${ }^{1}$. Using several sensors simultaneously, each of which is selectively sensitive to the particular chemical component, considerably enhances possibilities of the measuring system. The most attractive system of fiber-optical sensors is that, in which the principles of measurement of each sensor coincide. In this case, usually, in the role of sensitive elements the materials of one class are used ${ }^{2-4}$.

The advantages of using one class materials for determination of chemical components of solutions or gases are:

- possibility to use the unified technology for obtaining the sensitive elements;

- investigated properties and characteristics of these materials;

- possibility to adjust the parameters with the help of introduction of the chemical additives and operating practices of obtaining these sensitive elements.

Very often interaction of a sensitive elements with the chemical solutions leads to simultaneous change of different optical parameters (for instance, transmission spectrums, coefficient of refraction, temporary characteristics of optical processes), and various chemical components of a solution influence various optical parameters in a different way. Several measurements schemes are necessary for their registration, which makes the system of measurement technically more complicated, but enhances its possibilities and application areas in several times.

Bacteriorhodopsin (BR) is a perspective material for creation of sensitive elements of fiber-optical chemical sensors. Bacteriorhodopsin is a photosensitive protein, on the base of which films are created, and which optical parameters can be changed, depending on matrixes, chemical additives and the technology of films obtaining. Due to its nature, structure and chemical composition, BR and films on its base are sensitive materials to the external physicochemical conditions, and this predetermines possibility of using it as sensitive element for optical sensors. 


\section{DESCRIPTION OF FIBER-OPTIC SYSTEM OF CHEMICAL SENSORS}

A Fiber-optic sensor system for measurement of quality and quantity of composition of solutions is offered and approved. The system is constructed with $\mathrm{N}+1$ fiber-optical sensor (where $\mathrm{N}$ - number of registered chemical components), with sensitive elements as film deposited at the optical fibers end. Each separate film element is selectively sensitive to a particular chemical component. In the offered system two types of measurement techniques - amplitude and (or) interference are possible. The principle of work of each sensor is measurement of change of the reflection index on the border of a fiber end-film interface (for amplitude type sensor) or change of interference signal, caused by change of refraction index or thickness of a film (for interference type sensor), due to the selective interaction with one of the components of a chemical solution. Except of $\mathrm{N}$ selectively sensitive sensors, the system contains one amplitude optical-fiber end sensor without a chemically sensitive film element. The specified sensor, amplitude type, registers the change of reflection index on fiber end-investigated medium interface caused by change of refraction index of medium due to changing of common chemical composition.

Depending on the measured chemical component, the films with compositions sensitive to this component were deposited by appropriate technology as described below.

For the experiments with the amplitude fiber-optical sensors with films based on BR, the blue and yellow-green LEDs were used.

\section{PREPARATION AND CHARACTERIZATION OF SESNITIVE ELEMENTS}

Bacteriorhodopsin was extracted as purple membrane fragments (pmf) from Halobacterium salinarum, strain S9 cultured in our laboratory, according to standard procedures ${ }^{5,6}$. A suspension of BR and gelatin was prepared from $0.168 \mathrm{ml} \mathrm{BR}$ from a suspension of $0.5 \mathrm{mM} / \mathrm{ml} ; 0.248 \mathrm{ml}$ of $6 \% \mathrm{w} / \mathrm{v}$ hide gelatin (GE) or polyvinyl alcohol (PVA) (Sigma) and tridistilled water to give a final volume of $0.5 \mathrm{ml}^{7}$. Triethanolamine (TEA) (Sigma), dodecyl-trimethyl-ammonium-bromide (DTMAB), Largininehydrochloride $(\mathrm{AGH})$ was chosen as a sensitizing additives; the concentration of the chemical additives were in the range of 0.01-0.4 M. Film samples 10-20 $\mu \mathrm{m}$ thick were prepared by depositing the suspension onto $5 \mathrm{~cm}^{2}$ glass substrates or the end faces of $600 \mu \mathrm{m}$ quartz fibers by layering and drying, giving a sample of about 1 optical density, and kept at room temperature.

Porosity is an important parameter of film sensitive elements for gas sensors which defines the efficiency of sensors. Therefore, measurements of porosity of films used as matrixes for films based on BR were carried out.

The experiments were held using "Sorptomatic 1990" which is a completely computerized instrument based on a static volumetric principle to characterize solid samples by the technique of gas adsorption. The values of a specific surface area computed by a BET method ${ }^{8}$, for the gelatin films and PVA was 2,63 and 1,68 $\mathrm{m}^{2} / \mathrm{g}$ correspondingly. The values of a specific surface area computed by a $\mathrm{BJH}^{9}$ method were 3,45 and $2,93 \mathrm{~m}^{2} / \mathrm{g}$ correspondingly and are shown in the table 1 . From the obtained results it is evident that the specific surface area of GE films is larger than for PVA films, therefore the usage the gelatin matrixes is preferable due to higher porosity which allows more gases (or steams) penetrate into a film and this is very important for the sensors performance. The pore sizes distribution determined by the method of nitrogen desorption using the BJH method ${ }^{9}$. The pores sizes in gelatin and PVA films varies from 1 up to $200 \mathrm{~nm}$, and, the pores of 1,5 up to $50 \mathrm{~nm}$ predominate mainly. The films have strongly developed micro- and mesoporosity. The size of the pores in these films is small enough to make light scattering negligible.

\begin{tabular}{|c|c|c|c|}
\hline Sample name & $\begin{array}{c}\text { Specific surface area, } \\
\mathrm{m}^{2} / \mathrm{g}, \text { B.E.T }\end{array}$ & $\begin{array}{c}\text { Pore specific } \\
\text { volume }, \mathrm{cm}^{3} / \mathrm{g}\end{array}$ & $\begin{array}{c}\text { Specific surface area, } \\
\mathrm{m}^{2} / \mathrm{g}, \text { B.J.H }\end{array}$ \\
\hline Gelatin film & 2,63 & 0,003 & 3,45 \\
\hline PVA film & 1,68 & 0,001 & 2,93 \\
\hline
\end{tabular}

Table 1. Specific surface area and pore volume of gelatin and PVA films.

With the purpose to check the quality of a surface of obtained films based on BR, the analysis of surface morphology with the help of atomic-force microscope JSPM- 5210 is done. Results show that the surface of films based on bacteriorhodopsin is uniform for both GE (Fig. 1a) and for PVA (Fig.1 b) matrixes. 


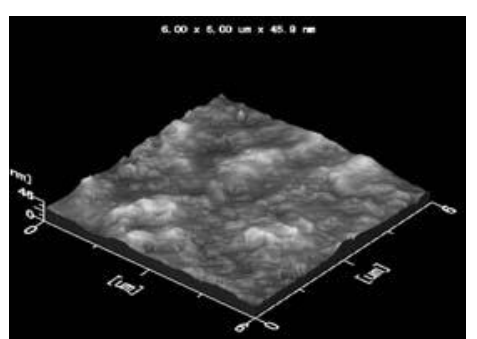

(a)

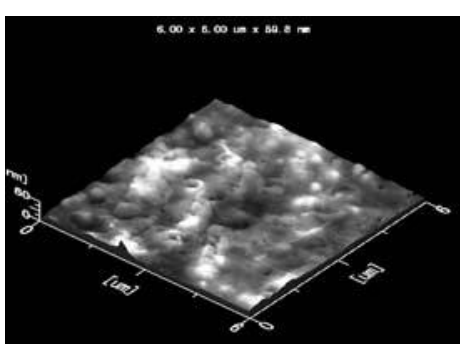

(b)

Fig. 1. Surface morphology of films based on bacteriorhodopsin in a gelatin matrix (a) and PVA matrix (b).

The results obtained before ${ }^{7}$, have shown that the atmosphere humidity considerably influences the transmission and halftime of $\mathrm{M}_{412}$ and $\mathrm{BR}_{570}$ intermediates. These changes significantly depend on composition of the chemical additives in films of bacteriorhodopsin in polymeric matrixes. The similar measurements of influence of gas-vapor components (Ammonia, $\mathrm{H}_{2} \mathrm{O}_{2}$, and Chlorine) on the photocycle parameters of films based on BR without and with various photosensitizing additives are shown below.

The presence of ammonia in the atmosphere surrounding the film resulted in changes of the optical transmittance and the photocycle parameters for both bacteriorhodopsin in a gelatin matrix and bacteriorhodopsin in a gelatin matrix with added TEA. The magnitudes of these changes were significantly different, however. Figs. 2 and 3 show the time dependence of transmission at 412 and $570 \mathrm{~nm}$ upon turning the actinic LED illumination on and then off. The kinetic changes at 412 and $570 \mathrm{~nm}$ confirm that the presence of ammonia results in changes in the bacteriorhodopsin photocycle for all the films investigated, but the sensitivity depends on film composition; in contrast to the humidity result, films without chemical additives are more sensitive to ammonia.

(a)

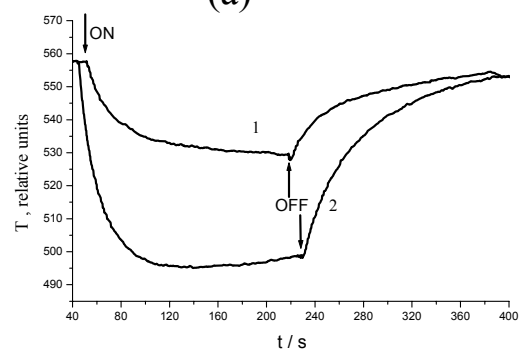

(b)

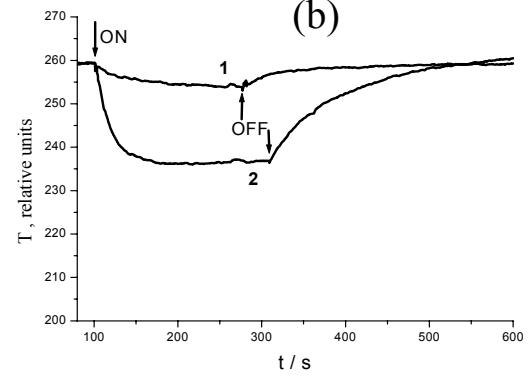

Fig. 2. Time dependence of transmission (T) changes of bacteriorhodopsin in gelatin matrix films at $412 \mathrm{~nm}$ during and after actinic illumination. 1, without ammonia; 2, with ammonia. (a) without TEA; (b) with added TEA.

(a)

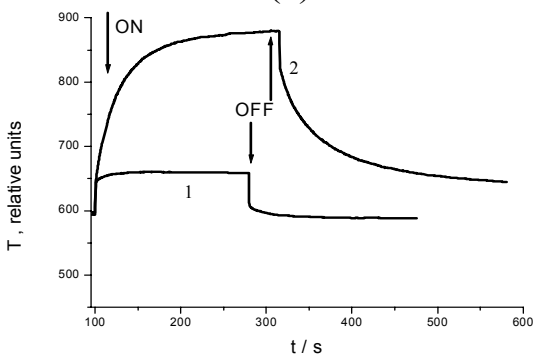

(b)

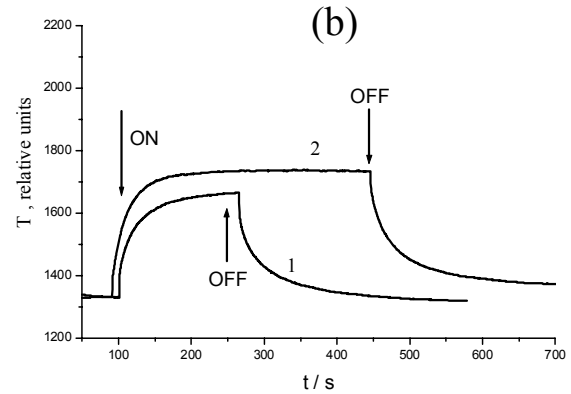

Fig. 3. Time dependence of transmission (T) changes of bacteriorhodopsin in gelatin matrix films at $570 \mathrm{~nm}$ during and after actinic illumination. 1, without ammonia; 2, with ammonia. (a) without TEA; (b) with added TEA. 


\begin{tabular}{|l|c|c|c|c|c|c|}
\hline \multirow{1}{*}{$\begin{array}{c}\text { Film } \\
\text { composition }\end{array}$} & \multicolumn{2}{|c|}{$\begin{array}{c}\text { Air, 50\% } \\
\text { relative } \\
\text { humidity }\end{array}$} & \multicolumn{2}{|c|}{ Ammonia } & \multicolumn{2}{|c|}{$\mathrm{H}_{2} \mathrm{O}_{2}$} \\
\cline { 2 - 7 } & $\begin{array}{c}\tau_{1 / 2} \\
(\mathrm{sec})\end{array}$ & $\begin{array}{c}\Delta \mathrm{T} \\
\%\end{array}$ & $\begin{array}{c}\tau_{1 / 2} \\
(\mathrm{sec})\end{array}$ & $\begin{array}{c}\Delta \mathrm{T} \\
\%\end{array}$ & $\begin{array}{c}\tau_{1 / 2} \\
(\mathrm{sec})\end{array}$ & $\begin{array}{c}\Delta \mathrm{T} \\
\%\end{array}$ \\
\hline $\mathrm{BR}+\mathrm{GE}+\mathrm{TEA}$ & 25 & 21 & 25 & 23 & 25 & 30 \\
\hline $\mathrm{BR}+\mathrm{GE}$ & 3 & 4 & 60 & 32 & 2,5 & 4,1 \\
\hline $\mathrm{BR}+\mathrm{GE}+\mathrm{AGH}$ & 13 & 6 & 44 & 36 & 11 & 7 \\
\hline $\begin{array}{l}\mathrm{BR}+\mathrm{GE}+\mathrm{TEA} \\
+\mathrm{AGH}\end{array}$ & 26 & 5,5 & 31 & 23 & 23 & 4 \\
\hline $\begin{array}{l}\mathrm{BR}+\mathrm{PVA}+ \\
\text { TEA }\end{array}$ & 16 & 51 & 20 & 48 & 13 & 39 \\
\hline
\end{tabular}

Table 2. Change of transmission and half-time of $\mathrm{BR}_{570}$ intermediate of films of different compositions in various gases during and after actinic illumination $(\lambda=570 \mathrm{~nm})$.

\begin{tabular}{|l|c|c|c|c|c|c|}
\hline \multirow{2}{*}{$\begin{array}{c}\text { Film } \\
\text { composition }\end{array}$} & $\begin{array}{c}\text { Air, 50\% } \\
\text { relative } \\
\text { humidity }\end{array}$ & \multicolumn{2}{|l|}{ Ammonia } & \multicolumn{2}{|c|}{$\mathrm{H}_{2} \mathrm{O}_{2}$} \\
\cline { 2 - 8 } & $\begin{array}{c}\tau_{1 / 2} \\
(\mathrm{sec})\end{array}$ & $\begin{array}{c}\Delta \mathrm{T} \\
\%\end{array}$ & $\begin{array}{c}\tau_{1 / 2} \\
(\mathrm{sec})\end{array}$ & $\begin{array}{c}\Delta \mathrm{T} \\
\%\end{array}$ & $\begin{array}{c}\tau_{1 / 2} \\
(\mathrm{sec})\end{array}$ & $\begin{array}{c}\Delta \mathrm{T} \\
\%\end{array}$ \\
\hline $\mathrm{BR}+\mathrm{GE}+\mathrm{TEA}$ & 31 & 6 & 28 & 11 & 65 & 5 \\
\hline $\mathrm{BR}+\mathrm{GE}$ & 24 & 2,4 & 49 & 11 & 19 & 5 \\
\hline $\mathrm{BR}+\mathrm{GE}+\mathrm{AGH}$ & 18 & 3 & 26 & 12 & 21 & 4 \\
\hline $\begin{array}{l}\mathrm{BR}+\mathrm{GE}+\mathrm{TEA}+ \\
\text { AGH }\end{array}$ & 24 & 4 & 41 & 14 & 18 & 6 \\
\hline $\mathrm{BR}+\mathrm{PVA}+\mathrm{TEA}$ & 36 & 14 & 28 & 17 & 36 & 13 \\
\hline
\end{tabular}

Table 3. Change of transmission and half-time of $\mathrm{M}_{412}$ intermediate of films of different compositions in various gases during and after actinic illumination $(\lambda=570 \mathrm{~nm})$.

The researches of chlorine effect on photocycle have shown, that the most sensitive are samples of $B R+G E+T E A+D T M A B$ composition.

The obtained results show, that for various films compositions the change of optical parameters depends on an environment, and the value of these changes varies as well.

\section{COCNLUSIONS}

Film based on photosensitive bacteriorhodopsin in polymer matrixes has good optical quality and strongly developed microand mesoporosity. The parameters of photocycle of films are influenced by an environment and chemical photosensitizing additives. The results obtained indicate that the additive selectively influenced the value of changes of photocycle parameters due to effect of the gas-vapor environments. It enables to create selectively sensitive to gases elements of fiber-optical sensors on the fiber end using gelatin matrix and bacteriorhodopsin as a basic.

\section{REFERENCE}

1. E. Udd, "Fiber Optic Sensors: An Introduction for Engineers and Scientists", Wiley-Interscience, 1 st edn., 1991.

2. J. White, J. S. Kauer, "Rapid analyte recognition in a devise based on optical sensors and the olfactory system", Anal Chem. 1996, vol. 68, pp. 2191-2202.

3. R. Paolesse, C. Di Natale, A. Macagnano, S. Nardis, A. D’Amico, A. A. Mencaglia, P. Bizzari and A.G. Mignani, "Toward an artificial olfactory perception: a fiber-optic spectroscopic platform for interrogating an array of optochemical sensors", Proc. of $16^{\text {th }}$ International Conference on Optical Fiber Sensors (OFS-16), IEICE Ed., 2003, pp. 742-745.

4. O.S. Wolbeis, "Fiber-optic chemical sensors and biosensors" (biannual review), Anal. Chem., 2002, vol. 74, pp. 2663-2677.

5. A. Kikineshy, Z. Bathori-Tarczy and Y. Sharkany, "Materials and devices for fiber optic sensors", In: W.K. Jones, G. Harsanyi (eds), NATO ASI Series 3, High Technology Dordrecht: KLUWER (1996) 181-184.

6. D. Oesterhelt and W. Stoeckenius, "Isolation of the cell membrane of Halobacterium halobium and its fractionation into red and purple membrane", Methods Enzymol., 31 (1974) 667 - 678.

7. J.P. Sharkany, S.O. Korposh, Z.I. Batori-Tarci, I.I. Trikur, J.J. Ramsden, ”Bacteriorhodopsin-based biochromic films for chemical sensors", Sens. Actuators B, 2004 (in press).

8. S. Brunauer, P.H. Emmet and E.Teller, “Adsorption of gases in multimolecular layers”, J. Amer. Chem. Soc., 60 , 309 (1938).

9. E.P. Barret, L.G. Joyner and P.P. Halenda, "The determination of pore volume and area distribution in porous substances. I. Computation from nitrogen isotherm”, J. Amer. Chem. Soc., 73, 373 (1951). 